\title{
Algılayıcı Türlerinin Güneş Takip Sisteminde Etkinliğinin Araştırılması
}

\author{
Tuğba Gürsoy ${ }^{1 *}$, Ahmet Yönetken ${ }^{2}$

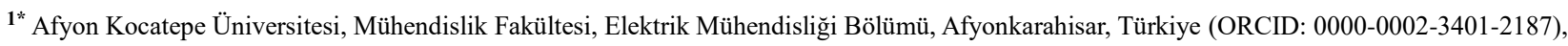 \\ yonetken@aku.edu.tr \\ ${ }^{2}$ Afyon Kocatepe Üniversitesi, Mühendislik Fakültesi, Elektrik Mühendisliği Bölümü, Afyonkarahisar, Türkiye, (ORCID: 0000-0003-1844-7233), \\ tubagrsoy_035@hotmail.com
}

(İlk Geliş Tarihi 19Aralık 2020 ve Kabul Tarihi 2 Haziran 2021)

(DOI: 10.31590/ejosat.843262)

ATIF/REFERENCE: Gürsoy, T. \& Yönetken, A. (2021). Algılayıcı Türlerinin Güneş Takip Sisteminde Etkinliğinin Araştırılması. Avrupa Bilim ve Teknoloji Dergisi, (25), 112-119.

\section{$\ddot{O} \mathbf{z}$}

Teknolojinin gelişmesi, enerjiye olan talep gün geçtikçe artmaktadır. Fosil yakıtların sınırlı olması alternatif enerji kaynakları aramaya teşvik etmektedir. Yenilenebilir enerji kaynakları kullanımı artan enerji talebini karşılamada önemli bir yere sahiptir. Güneş enerji teknolojileri günümüzde sıkça kullanılmaya başlanmıştır. Güneş enerjisinden yüksek verimlilikle güç elde etmede güneş takip sistemleri gündeme gelmektedir. Bu çalışmada Güneş takip sistemleri çift eksenli olarak tasarlanmıştır. Güneş panelleri aynı teknik özelliklere sahiptir. Güneş panellerine üzerine üç farklı tip algılayıcı yerleştirilmiştir. Algılayıcı türlerinin aynı tip enerji üretimine olan performansları karşılaştırılmıştır. Sistemin sabit ve hareketli konumda belirli aralıklarla gerilim ve akım değerleri ölçülmüştür. Elde edilen verilere göre güneş panellerinin sabit ve hareketli konumda toplam üretimleri karşılaştırıldığında hareketli konumda sabit konuma göre; LilyPad Işık Sensörlü sistemde \%36,68 oranında, SMD Sensörlü sistemde \%38,42 ve LDR'li sistemde \%43,58 oranında artı̧̧ görülmüş̧ür.

\section{Investigation Of The Activities Of Sensor Types In Solar Tracking System}

\begin{abstract}
The development of technology and the demand for energy are increasing day by day. The limited fossil fuels encourage the search for alternative energy sources. The use of renewable energy sources has an important place in meeting the increasing energy demand. Solar energy technologies are being used frequently today. Solar tracking systems are on the agenda in obtaining power from solar energy with high efficiency. In this study, solar tracking systems are designed as biaxial. Solar panels have the same technical features. Three different types of sensors are placed on the solar panels. The performances of the sensor types against the same type of energy production have been compared. The voltage and current values of the system were measured in fixed and mobile positions at regular intervals. According to the data obtained, when the total productions of solar panels in fixed and mobile position are compared; There was an increase of \%36.68 in the LilyPad Light Sensor system, \%38.42 in the SMD Sensor system and \%43.58 in the system with LDR.
\end{abstract}

Keywords: Renewable energy, Solar tracking systems, Sensors.

*Sorumlu Yazar:yonetken@aku.edu.tr 


\section{Giriş}

Güneş enerjisi temiz ve sonsuz bir kaynaktır. Artan enerji ihtiyacını karşılamada önemli bir yere sahiptir. Güneş enerjisinin ışınım şiddetinin sürekli ve aynı değerde olmaması bu sistemlerden maksimum verimle enerji üretimini mümkün kılmamaktadır. Enerjinin belli aralıklarda farklı değerlere sahip olması sistemden anlık olarak yüksek verimlilikle enerji üretimi sağlamayı gerektirir. Güneş 1şınlarının geliş açısı her saat aralığında değişkenlik göstermektedir. Güneş 1şııı panel yüzeyine dik açıda geldiği konumda sistem en yüksek verimlilikle çalışmaktadır. Güneş ışınlarını her konumda dik açıda alabilmek için güneş takip sistemleri kullanılmaktadır. Bu sistemler sabit sistemlerden farklı olarak hareketli bir yapıya sahiptir. $\mathrm{Bu}$ sayede güneş ışınlarının geliş açısına doğru yönelerek sistemin maksimum verimlilikle üretim yapmasına olanak sağlamaktadır. Sistemin yüksek verimlilik sağlamasına karşın hareket mekanizması ve güneş 1şı̆̆ı algılama donanımları ekstra bir maliyet ortaya çıkarmaktadır. Güneş takip sistemlerinin konumlandırılması detaylı bir fizibilite çalışması gerektirmektedir. Güneş takip sistemlerinin konumlandırılmasının iyi yapılamaması bu sistemlerden alınan verimin düşmesine sebebiyet verebilmektedir. Güneş takip sistemlerinden yüksek verimlilikle enerji üretimi için pek çok çalışma yapılmaktadır. Aşağıda bu tür çalışmalara örnek verilebilir:

Alif Ismail ve arkadaşları, ayna yansımalı bir çift eksenli güneş takip sistemi tasarlamışlardır. Sistemde $10 \mathrm{~W}$ güneş paneli, servo motor, LDR (Işığa Bağımlı Direnç) ve aurdino uno kullanılmıştır. Deneyin sonuçlarına göre tasarlanan sistemin sabit sisteme göre daha iyi performans gösterdiği sonucuna varılmıştır (Alif Ismail et al, 2020). Allamehzadeh çalışmasında güneş enerjisi ve güneş takip sistemleri teknolojileri hakkında inceleme yapmıştır. Araştırma sonucunda güneş takip sistemlerinin sabit sistemlere göre verimlilik açısından daha iyi olduğu sonucuna varılmıştır (Allamehzadeh, 2019). Al-Rousan ve arkadaşları, ANFIS (Uyarlamalı Ağ Bulanık Çıkarım Sistemi) prensibini kullanarak iki adet akıllı güneş takip kontrol sistemi önermişlerdir. Önerilen modellerde güneş 1şınımı maksimum seviyede alarak güneş takip sisteminin performansını arttırmak amaçlanmıştır. Deney sonuçları doğrultusunda önerilen sistemlerin güneş takibi kontrolü için optimum seviyede olduğu gözlemlenmiştir (Al-Rousan et al, 2020). Altayeb ve arkadaşları, iki eksenli bir güneş takip sistemi tasarlamışlardır. Sistem mikrodenetleyici ile kontrol edilmiştir. Güneş takibini yapabilmek için üç tip güneş izlemi yöntemi kullanılmıştır. Veri toplama aşamasında özel bir yazılım kullanarak sistemin bütün çıktıları analiz edilmiştir (Altayeb et al, 2018).

Amelia ve arkadaşları, panellerin optimum seviyede güneş 1şını alması için mevcut güneş takip sistemlerini incelemişlerdir. Mevcut sistemlerin performans analinizi yapılmış, avantaj ve dezavantajlarına değinilmiştir. Araştırma sonucunda en verimli sistemin çift eksenli rotasyon ile aktif güneş takip sistemleri olarak belirlenmiştir (Amelia et al, 2020). Ammach ve Attia, iki eksenli güneş takip sistemi önermişlerdir. Tasarımda iki adet DC (Doğru Akım) motor ile gün içinde otomatik olarak panel konumlandırılmıştır. Güneş panelini güneşin koordinatlarına yönlendirmek için mikrodenetleyici algoritması kullanılmıştır. Mekanizma kullanılmadığı zamanlarda uyku moduna geçmektedir. $\mathrm{Bu}$ sayede düşük güç tüketimi sağlanmıştır. Önerilen güneş takip sistemi Cidde, Suudi Arabistan bölgesi için uygulanmış ve başarılı sonuçlar elde edilmiştir (Ammach \&

e-ISSN: 2148-2683
Attia, 2019). Awad ve arkadaşları, aurdino kullanarak ekonomik bir güneş takip sistemi geliştirmiştir. Sistemde mekanizma hareketi için servo motor, LDR (Işı̆̆a Bağımlı Direnç) ve 1şı̆̆a bağlı olarak sistemi konumlandırmak için mikrodenetleyici kullanılmıştır. Deneysel sonuçlar önerilen sistemin aynı şartlarda sabit bir güneş panelinden $\% 25$ daha verimli olduğunu göstermiştir (Awad et al, 2020). Awasthi ve arkadaşları, mevcut güneş paneli sistemlerini ve güneş takip sistemlerini incelemişlerdir. Çift eksenli güneş takip sistemleri üzerinde durmuşlardır. Genel olarak bu sistemlerin tek eksenli ve sabit sistemlere göre daha verimliği olduğu sonucuna varılmıştır (Awasthi et al, 2020). Away and Ikhsan, çift eksenli güneş takip sistemleri için yeni bir güneş 1 şı̆̆ 1 algılama sensörü önermiştir. Sensörde dört yüzlü şekil üstüne üç adet LDR (Işığa Bağımlı Direnç) yerleştirilmiştir. Sistemde maksimum görüş alanı sağlanarak hataları en aza indirmek amaçlanmıştır. Geliştirilen sensör başarılı sonuçlar vermiştir (Away \& Ikhsan, 2017). Benaboud, MPPT (Maksimum Güç Noktası İzleyici) teknikleri ile kontrol edilebilen birçift eksenli güneş takip sistem önermiştir. Önerilen prototipte MPPT (Maksimum Güç Noktası İzleyici) tekniklerinin kullanılması panelin güneş 1şınını maksimum seviyede almasını sağlamıştır (Benaboud, 2020). Farhan, düşük maliyetli çift eksenli bir güneş takip sistemi tasarlamıştır. Sistemde mekanizmayı konumlandırmak için DC (Doğru Akım) motor ve 1şı ğı algılama için LDR (Işığa Bağımlı Direnç) kullanmıştır. Elde ettiği sonuçlara göre çift eksenli güneş takip sisteminin diğer sistemlerden daha verimli olduğunu belirlemiştir (Farhan, 2020). Jamroen ve arkadaşları, düşük maliyetli bir güneş takip sistemi önermişlerdir. Takip sistemi çift eksenli olup kapalı döngü kontrol etmişlerdir. Sisteme girdi olarak LDR (Işığa Bağımlı Direnç) sensörlerden alınan bilgiler kullanılmıştır. Önerilen takip sistemi sabit PV sistemi ile karşılaştırılmıştır. Elde edilen sonuçlara göre önerilen sistemin verimliliği ortalama $\% 44,89$ arttırdığı görülmüştür. Tasarlanan sistemin maliyet analizi yapılmıştır (Jamroen et al, 2020). Makhija ve arkadaşları, çalışmalarında otomatik bir çift eksenli güneş takip cihazı tasarımı yapmışlardır. Güneş takip devresinde arduino, dört adet LDR (Işığa Bağımlı Direnç) ve iki adet servo motor kullanılmıştır. Sistem çıktısının verimliliği, 20 derecelik bir açıyla eğimli sabit bir güneş paneli ile karşılaştırılmıştır. Elde edilen sonuçlar çift eksenli güneş takip sisteminin \%37 daha yüksek voltaja ulaştığını göstermiştir (Makhija et al, 2017). Mane ve arkadaşları, bu çalışmada çift eksenli güneş takip sisteminin simülasyon modelini sunmuşlardır. Çift eksenli güneş takip sisteminin ürettiği güç, deney süresi boyunca sabit güneş panelinden \%26,72 daha fazla olmuştur (Mane et al, 2018).

Mohaimin ve arkadaşları, çalışmalarında güneş takip sistemlerinin uygulanabilirliği konusunda farklı bir yöntem önermektedir. Tek eksenli takip için iki adet LDR (Ișı ğa Bağımlı Direnç) ve motor, çift eksenli takip içinse dört adet LDR (Işı̆̆a Bağımlı Direnç) ve iki motor kullanılmaktadır. Her iki sistem için mikrodenetleyici ile akım, gerilim ve güç değerleri okunur. Okunan değerler Proteus simülasyon programı kullanılarak karşılaştırılmıştır. Ölçülen değerler \%1.4'lük bir hata payına sahiptir (Mohaimin et al, 2018). Mohaimin ve arkadaşları, mikrodenetleyici kullanarak iki eksenli güneş takip sistemi tasarlamışlardır. Sistemden her 10 saniyede bir veri alınmış ve veriler hafıza kartına kaydedilmiştir. Elde edilen sonuçlara göre çift eksenli güneş takip sistemi, tek eksenli güneş takip sisteminden $\% 8$ ila\%12 daha fazla güç üretmiştir (Mohaimin et al, 2018). Mohd Said ve arkadaşları, aurdino kullanarak IOT (Nesnelerin İnterneti) izleme sistemi ile çift eksenli güneş takip sistemi tasarlamışlardır. Sistemde mekanizmayı döndürmek için 
iki adet servo motor ve güneş 1şığı algılama için 4 adet LDR (Işı̆ğa Bağımlı Direnç) kullanılmıştır. Wi-fi ESP8266 cihazı kullanılarak cihaz ile izleme sistemi arasında haberleşme sağlanmıştır. Sistem sonuçları elde edilmiş ve tek eksenli güneş takip sistemi ile karşılaştırılmıştır. Sonuçlar çift eksenli güneş takip sisteminin güç çıktısının daha fazla olduğunu göstermiştir (Mohd Said et al, 2020). Mustafa ve arkadaşları, hassasiyeti yüksek bir güneş takip sistemi tasarlamışlardır. Bu çalışmada güneş pozisyonunu algılamak için iki aşama kullanılmıştır. Deney sonuçları güneş takip sisteminin verimliliği arttığını göstermiştir (Mustafa et al, 2017). Mustafa ve arkadaşları, dişli sistemine sahip bir mekanik sistem üzerinde LDR (Işı̆ga Bağımlı Direnç) ve DC (Doğru Akım) motor kullanarak çift eksenli güneş takip sistemi tasarlamışlardır. Deney sonuçları güneş takip sisteminin verimliliği arttırdığını göstermiştir (Mustafa et al, 2018). Natarajan ve arkadaşları, çalışmalarında su kütlelerine kurulabilen çift eksenli bir güneş takip sistemi tasarımı yapılmıştır. Mekanizmada step motor ve aktüatör kullanılmıştır. Tasarımda platform için farklı malzemelerin özellikleri karşılaştırılmıştır. Prototip ahşap malzemeden yapılmış ve tasarımı geliştirilmiştir (Natarajan et al, 2019). Pattanaik, güneş paneline gelen maksimum güneş 1 şı̆̆ını saptamak için bir otomatik kontrol sistemi tasarlamıştır. Güneş takip sisteminde iki adet DC (Doğru Akım) servo motor ve dört adet LDR (Işığa Bağımlı Direnç) kullanmıştır. Akım ve gerilim değerleri arduino mikro denetleyicisi tarafindan okunmuştur (Pattanaik, 2019). Salih ve arkadaşları çalışmalarında MPPT (Maksimum Güç Noktası İzleyici) algoritması kullanarak güneş takip sisteminin üretimini gözlemlemişlerdir (Salih et al, 2019). MPPT (Maksimum Güç Noktası İzleyici) ile takip sisteminin geleneksel sistemlere göre daha yüksek verimlilikle enerji üretimi yaptığı saptanmıştır (Jin et al, 2019). Smirnov ve arkadaşları, Chelyabinsk'te bulunan bir panel için tek eksenli güneş takip sisteminin etkinliğini araştırmışlardır. Mayıs-Eylül 2016 döneminde dört adet deney setinden veri almışlardır. Elde edilen veriler sabit panele göre verimliliğin \%33 arttırılabildiğini göstermiştir (Smirnov et al, 2020). Tiwari ve arkadaşları, Matlab ortamında iki eksenli bir güneş takip sistemi simülasyonu yapmışlardır. PV (Fotovoltaik) sistemi, kontrol devresi, LDR (Işığa Bağımlı Direnç) sensörü gibi tüm donanımlar simülasyon ortamında geliştirilmiştir. Sistemden farklı günlerde veriler alınmıştır. Modelden alınan verilerle sabit sistemin verileri karşılaştırılmıştır. Elde edilen sonuçlar güneş takip sisteminin verimliliği arttığını göstermiştir (Tiwari et al, 2020). Zhu ve arkadaşları, bu çalışmada yeni bir izleme sistemine dayanan tek eksenli bir güneş takip sisteminin tasarımını ve performans analizini sunmuşlardır. Güneşin koordinatları ve güneş radyasyonu tahmin metoduna dayalı bir model önermişlerdir. Modelin benzetim sonuçları önerilen sistemin mevcut sistemlere göre avantajlı olduğunu göstermektedir (Zhu et al, 2020).

Güneş takip sistemleri konusuyla alakalı literatürde pek çok çalışma mevcuttur. Yapılan çalışmalar güneş takip sistemlerinin, sabit sistemlere göre yüksek verimlilikle çalıştığını gösterir niteliktedir. Güneş takip sistemlerini geliştirmek için farklı metodolojiler önerilmektedir. Güneş ışığını maksimum seviyede alabilmek için farklı algoritmalar geliştirilmektedir. Sistemlerde genellikle güneş 1şı̆̆ını algılamak için LDR (Işı̆̆a Bağımlı Direnç) kullanılmıştır. Bu çalışmada çift eksenli güneş takip sisteminde algılayıcıların verimliliği karşılaştırılmıştır. Deney için üç adet çift eksenli güneş takip sistemi tasarlanmıştır. Tasarlanan her sisteme aynı özellikte $100 \mathrm{~W}$ gücünde güneş panelleri monte edilmiştir. Sistemin sabit konumda 12 Ağustos 2019 - 01 Eylül 2019 tarihleri arasında belirli aralıklarla akım ve e-ISSN: 2148-2683 gerilim değerleri kaydedilmiştir. Daha sonra üç farklı değerlere sahip algılayıcılar monte edilmiştir. Üç ayrı sistem aynı koşullarda çalıştırılmış ve hareketli sistemin 02 Eylül - 22 Eylül 2019 Tarihleri arasındaki akım ve gerilim değerleri kaydedilmiştir. Sabit ve hareketli konumdaki değerler yapay sinir ağları ile bir tahmin yapılmıştır. Elde edilen verilere göre algılayıcıların verimlilikleri kıyaslanmıştır. Çalışmada güneş panellerinin sabit ve hareketli konumda toplam üretimleri karşılaştırıldığında hareketli konumda sabit konuma göre; LilyPad Işık Sensörlü sistemde \%36,68 oranında, SMD Sensörlü sistemde $\% 38,42$ ve LDR'li sistemde \%43,58 oranında artış görülmüştür. $\mathrm{Bu}$ makalenin organizasyonu aşağıdaki şekilde tasarlanmıştır. 2.Bölümde çalışmada kullanılan güneş paneli, güneş panelini taşıyan platform, algılayıcılar, ölçme donanımları, enerji üretim tahmini hakkında bilgi verilmiştir. Güneş panelinin teknik özellikleri belirtilmiştir. Güneş panelini taşıyan platformun özellikleri açıklanmıştır. Sistemde kullanılan algılayıcıların teknik özellikleri sunulmuştur. Ölçme donanımlarının blok diyagramı verilmiştir. Enerji üretim tahmini kısmında kullanılan yöntem hakkında açıklama yapılmıştır. 3.Bölümde çalışmadan elde edilen bulgular tablo ve grafiklerle sunulmuş ve son olarak 4.Bölümde literatürde yapılmış çalışmalarla elde edilen sonuçlar tartışılmıştır. Sistemle ilgili tavsiyelerde bulunulmuştur.

\section{Materyal ve Metot}

\subsection{Güneş Paneli}

Güneş panelleri, güneş enerjisinden elektrik üretmek için kullanılan bir malzemedir. Özelliklerine göre birçok çeşidi mevcuttur. Güneş enerji paneli çeşitleri arasında Monokristal en verimli olanıdır. Fakat maliyeti açısından diğer panellere göre daha pahalıdır. Bu güneş paneli türü küçük alanda yüksek enerji üretir. Güneş enerji potansiyeli düşük bölgelerde enerji üretimi için alternatif olabilmektedir. $\mathrm{Bu}$ panellerin kullanım ömrü uzundur. Ancak gölgelenme faktörü panelin verimli çalışmasını olumsuz etkilemektedir. Kısa sürede az yüzey alanıyla yüksek güç çıktıları elde etmek için çalışmada monokristal panel tercih edilmiştir. Her biri $100 \mathrm{~W}$ gücünde üç adet güneş paneli kullanılmıştır. Panellerin teknik özellikleri Tablo 1'de verilmiştir.

Tablo 1. Güneş panelinin teknik özellikleri

\begin{tabular}{l|c}
\hline PV Model & SRM-100D \\
\hline Standart güç & $100 \mathrm{~W}$ \\
\hline Kısa devre akımı (Isc) & $5.51 \mathrm{~A}$ \\
\hline Açık devre voltajı (Voc) & $24.35 \mathrm{~V}$ \\
\hline $\begin{array}{l}\text { Maksimum güç noktası akımı } \\
\text { Imp) }\end{array}$ & $5.06 \mathrm{~A}$ \\
\hline $\begin{array}{l}\text { Maksimum güç noktası } \\
\text { voltajı (Vmp) }\end{array}$ & $19.8 \mathrm{~V}$ \\
\hline $\begin{array}{l}\text { Maksimum sistem voltajı } \\
\text { Modül boyutu }\end{array}$ & DC 1000 V \\
\hline
\end{tabular}

\subsection{Güneş Panelini Taşıyan Platform}

Güneş enerji sistemlerinde verimliliği arttırmaya yönelik uygulamalarda güneş takip sistemleri gündeme gelmektedir. 
Güneş takip sistemleri gün boyu güneşten yararlanma sağladığ1 için verimliliği arttırmaktadır. Ancak bu sistemlerin gün boyu güneş 1şı̆̆ını takip etmesi için mekanizma maliyeti yüksektir. Güneş takip sistemleri takip ekseni ve kontrol yöntemine göre farklılık göstermektedir. Çalışmada çift eksenli bir güneş takip sistemi tasarlanmıştır. Tasarlanan deney düzeneği Şekil 1'de verilmiştir.
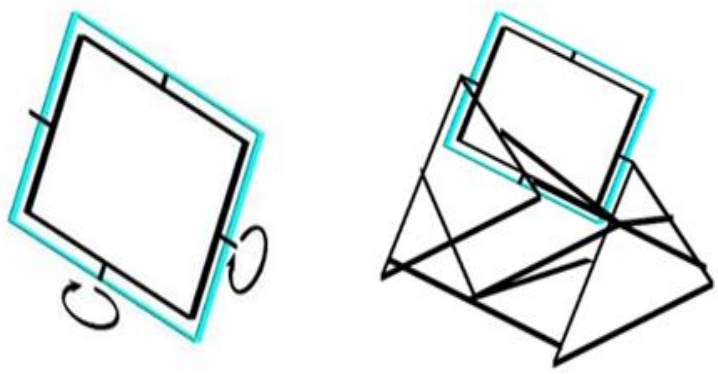

Şekil 1. Tasarlanan deney düzeneğ $i$

Güneş takip sistemlerinin mekanik aksamında güneş takip sisteminin hareketini sağlamak için yüksek torklu MG995 servo motor seçilmiştir. Tasarım panelin boyutlarına göre dizayn edilmiştir. Dizayn edilen sistem deneyi yapmaya uygun olmakla beraber düşük maliyetli bir sistemdir. Sistem yere sabitlenmesini sağlayan ayaklar ve panellerin monte edildiği çerçeve olarak iki kısımdan oluşmaktadır. Yere sabitlenmesini sağlayan kısım panelin boyutlarına göre dengede durabilecek ve motora ekstra bir yük bindirmeyecek şekilde hesapları yapılmıştır. Panel boyutunun uzun olması nedeniyle sistemde hareket mekanizmasında yüksek güçlü motor kullanmamak için sistem yatay eksende tasarlanmıştır. Sistemde iki adet çerçeve bulunmaktadır. Diş çerçeve doğu-batı yönünde hareketi sağlarken, panellerin monte edildiği iç çerçeve kuzey-güney yönündeki dönüşü sağlamaktadır. Çerçevelerin bir tarafında motor bağlantısı bulunurken karşı tarafinda ise rulmanlar bulunmaktadır. $\mathrm{Bu}$ sayede motor hareketiyle çerçeveler 1 şı sensörlerinden aldığı bilgiye göre sistemin istenilen yöne çevrilmesini sağlamaktadır.

Panellerin ürettiği enerji çıktıları sabit ve hareketli olmak üzere her iki durumdada aynı platform üzerinden alınmıştır. İlk önce platformun hareket etmesini sağlayan kontrol sistemi devre dışı bırakılarak sabit konumda veri alınmıştır. Daha sonra platformun kontrol sistemi devreye alınarak hareketli konum verileri kaydedilmiştir.

\subsection{Algilayıcilar}

Algılayıcılar fiziksel bir giriş bilgisini çıkış sinyaline dönüştüren cihazlardır. Kullanım amacına göre çeşitli sensörler mevcuttur. Güneş takip sistemlerinde de 1 şı sensörleri kullanılabilmektedir. Çalışmada güneş ışığına göre güneş takip sistemini yönlendirmek için LDR (Işığa Bağımlı Direnç), ALSPT19-315C SMD (Yüzeye Monte Edilebilen Eleman) Işık sensörü ve LilyPad Işık Sensörü olmak üzere üç farklı algılayıcı kullanılmıştır. Her sistemde ayrı bir algılayıcı kullanılmıştır.

LDR (Işı̆̆a Bağımlı Direnç) bir foto dirençtir. Foto dirençler 1ş1k şiddetine bağlı olarak direnci değişen pasif bir sensördür. Bulunduğu devrede değişkenlik gösteren direnç değerleri ile bir çıkış sağlar. LDR'ler sistemde dış ortamdan aldıkları fiziksel bir değişim ile sensör olarak görev yapar. LDR'lerin elektriksel özellikleri Tablo 2'de verilmiştir.
Tablo 2. LDR'nin elektriksel özellikleri

\begin{tabular}{l|c|c|c|c|c}
\hline Parametre & Conditions & Min. & Typ. & Max. & Units \\
\hline $\begin{array}{l}\text { Cell } \\
\text { Resistance }\end{array}$ & $1000 \mathrm{lux}$ & - & 400 & - & $\Omega$ \\
\hline $\begin{array}{l}\text { Dark } \\
\text { Resistance }\end{array}$ & - & - & 9 & - & $\mathrm{k} \Omega$ \\
\hline Dark & - & - & 3.5 & - & $\mathrm{pF}$ \\
Capacitance & & & & & \\
\hline Rise Time 1 & $1000 \mathrm{lux}$ & - & 2.8 & - & $\mathrm{ms}$ \\
& $10 \mathrm{lux}$ & - & 18 & - & $\mathrm{ms}$ \\
\hline Fall Time 2 & $1000 \mathrm{lux}$ & - & 48 & - & $\mathrm{ms}$ \\
& $10 \mathrm{lux}$ & - & 120 & - & $\mathrm{ms}$ \\
\hline
\end{tabular}

ALS-PT19-315C SMD fototransistör çıkışlı optik sensördür. LDR (Işı̆̆a Bağımlı Direnç) ile aynı mantıkta çalışmaktadır. Bu analog 1ş1k sensörü genellikle küçük boyutta projelerde kullanılmaktadır. SMD'nin teknik özellikleri Tablo 3'te verilmiştir.

Tablo 3. SMD’lerin teknik özellikleri

\begin{tabular}{|c|c|c|c|c|c|c|}
\hline Parametre & Sym. & Min. & Typ. & Max & Unit & $\begin{array}{c}\text { Test } \\
\text { Condition }\end{array}$ \\
\hline $\begin{array}{l}\text { Dark } \\
\text { Current }\end{array}$ & $\mathrm{I}_{\mathrm{CEO}}$ & - & - & 0.1 & $\mathrm{uA}$ & $\begin{array}{l}\mathrm{V}_{\mathrm{CE}}=10 \mathrm{~V} \\
\mathrm{E}_{\mathrm{v}}=0 \mathrm{Lux}\end{array}$ \\
\hline $\begin{array}{l}\text { Collector- } \\
\text { Emitter } \\
\text { Saturation } \\
\text { Voltage }\end{array}$ & $\mathrm{V}_{\mathrm{CE}(\text { sat }}$ & - & - & 0.4 & $\mathrm{~V}$ & $\begin{array}{c}\mathrm{I}_{\mathrm{c}}=2 \mathrm{~mA} \\
\mathrm{E}_{\mathrm{v}}=1000 \mathrm{Lux}\end{array}$ \\
\hline Light Current & $\begin{array}{l}\mathrm{IPH}_{\mathrm{PH}} \\
\mathrm{I}_{\mathrm{PH} 2} \\
\mathrm{I}_{\mathrm{PH} 3}\end{array}$ & $\begin{array}{c}5 \\
50 \\
140\end{array}$ & $\begin{array}{c}15 \\
150 \\
520\end{array}$ & - & $\begin{array}{l}\mathrm{uA} \\
\mathrm{uA} \\
\mathrm{uA}\end{array}$ & $\begin{array}{c}V_{\mathrm{CE}}=5 \mathrm{~V} \\
\mathrm{E}_{\mathrm{v}}=100 \mathrm{Lx} \\
V_{\mathrm{CE}}=5 \mathrm{~V} \\
\mathrm{E}_{\mathrm{v}}=1000 \mathrm{Lx} \\
V_{\mathrm{CE}}=5 \mathrm{~V} \\
\mathrm{E}_{\mathrm{v}}=1000 \mathrm{Lx}\end{array}$ \\
\hline $\begin{array}{l}\text { Photocurrent } \\
\text { Ratio }\end{array}$ & $\mathrm{IPH}_{3} / \mathrm{IPH}_{2}$ & - & 3.5 & - & - & $\begin{array}{c}\mathrm{V}_{\mathrm{CE}}=5 \mathrm{~V} \\
\mathrm{E}_{\mathrm{v}}=1000 \mathrm{Lx}\end{array}$ \\
\hline $\begin{array}{l}\text { Saturation } \\
\text { Output } \\
\text { Voltage }\end{array}$ & $\mathrm{V}_{0}$ & 4.5 & 4.6 & - & $\mathrm{V}$ & $\begin{array}{c}V_{\mathrm{CC}}=5 \mathrm{~V} \\
\mathrm{E}_{\mathrm{v}}=1000 \mathrm{Lx} \\
\mathrm{R}_{\mathrm{L}}=75 \mathrm{~K}\end{array}$ \\
\hline
\end{tabular}

LilyPad Işık Sensörü, yerleşik ve hemen kullanıma hazır bir ALS-PT19 1şık sensörüne sahip, bir sensör kartıdır. Sensör, üzerinde parlayan ortam ışı̆̆ının seviyesine bağlı olarak 0V ile $5 \mathrm{~V}$ arasında voltaj üretir. Işık yoğunluğuna göre mikrodenetleyicinin çektiği akım artar. 360 ile 970 spektral algılama aralığına sahiptir. LilyPad Işık Sensörü'nün teknik özellikleri Tablo 4'te verilmiştir.

Tablo 4. LilyPad Işık Sensörü 'nün teknik özellikleri

\begin{tabular}{l|c|c|c|c}
\hline Parametre & $\begin{array}{c}\text { Test } \\
\text { Condition }\end{array}$ & Symbol & Value & Unit \\
\hline $\begin{array}{l}\text { Collector } \\
\text { Emitter } \\
\text { Voltage }\end{array}$ & & $\mathrm{V}_{\mathrm{CEO}}$ & 6 & $\mathrm{~V}$ \\
\hline $\begin{array}{l}\text { Emitter } \\
\text { Collector } \\
\text { Voltage }\end{array}$ & & $\mathrm{V}_{\mathrm{ECO}}$ & 1.5 & $\mathrm{~V}$ \\
\hline $\begin{array}{l}\text { Collector } \\
\text { Current }\end{array}$ & & $\mathrm{I}_{\mathrm{C}}$ & 20 & $\mathrm{~mA}$ \\
\hline $\begin{array}{l}\text { Total Power } \\
\text { Dissipation }\end{array}$ & $\mathrm{T}_{\mathrm{amb}} \leq 55^{\circ} \mathrm{C}$ & $\mathrm{P}_{\mathrm{tot}}$ & 100 & $\mathrm{~mW}$ \\
\hline
\end{tabular}




\section{4. Ölçme Donanımları}

Güneş takip sisteminin enerji çıttılarını saptamak için ölçme donanımı kullanılmaktadır. Sistemde akım ve gerilim ölçümü yapılmıştır. Ölçüm sistemi Arduino mikrodenetleyicisi ile programlanmıştır. Sistemde akım sensörü, gerilim bölücü dirençler, LCD ekran ve $\mathrm{Sd}$ kart modülü bulunmaktadır. Sistemin akım değerleri doğrudan ölçülebilirken gerilim değerleri dirençler üzerinden geçirilerek ölçülür. Elde edilen veriler ekran üzerinden izlenebilirken aynı zamanda bir dakikalık aralıklarla Sd kart içine kaydedilmiştir. Veri alma sisteminin blok diyagramı Şekil 2'de verilmiştir.

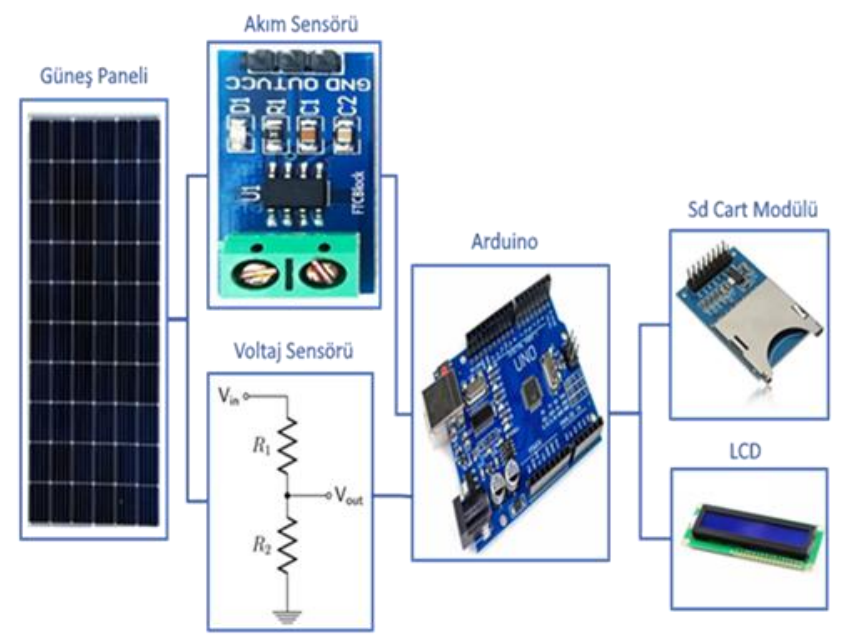

Şekil 2. Veri alma sistemin blok diyagramı

\subsection{Enerji Üretim Tahmini}

Güneş enerjisinin ışınım değerleri gün içinde belirli zaman aralıklarında değişkenlik göstermektedir. Gün boyu güneş enerji sistemlerinden sabit enerji üretimi yapılamamaktadır. Sistemin enerji çıktılarından yola çıkarak kısa ve uzun vadede üretim yapabilmek için birçok metodoloji mevcuttur. Yapay sinir ağları enerji üretim tahmininde yaygın olarak kullanılan bir tahmin yöntemidir. Yapay sinir ağlarında çok çeşitli ağ yapıları ve modelleri bulunmaktadır. Çalışmada girdi olarak sistemden alınan akım, gerilim değerleri ve ışınım değerleri kullanılarak kısa dönem tahmin yapılmıştır. Üretim değerlerinin karşılaştırılması Şekil 3’te verilmiştir.

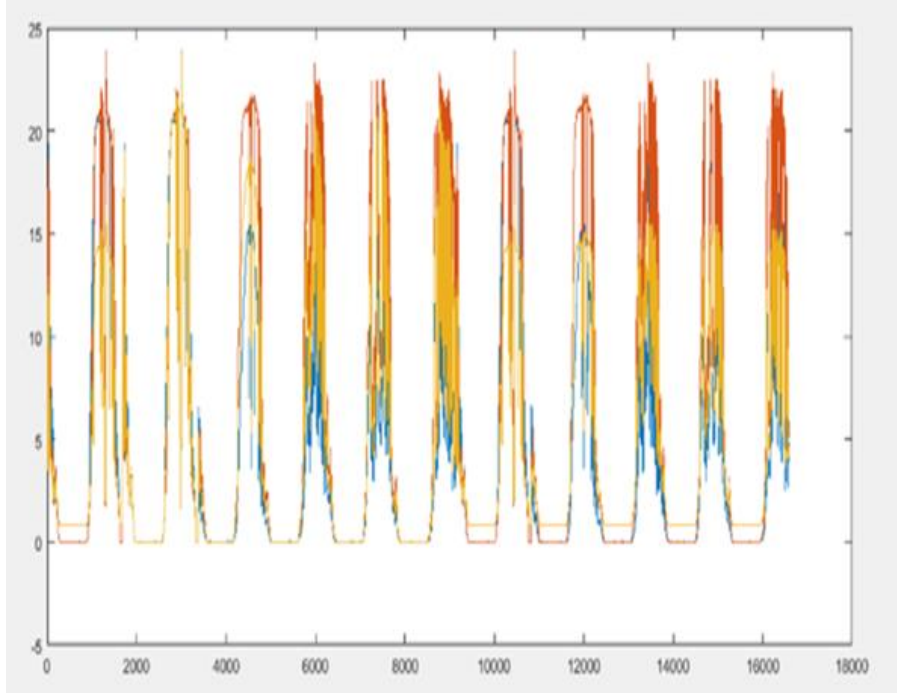

Şekil 3. Üretim değerlerinin karşılaş̧tırlması

\section{Araştırma Sonuçları ve Tartışma}

Çalışma Afyon Kocatepe Üniversitesi Güneş ve Rüzgar Enerjisi Araştırma ve Uygulama Merkezi'nin araştırma sahasında yapılmıştır. Kurulan sistemlerden 12 Ağustos 2019 -22 Eylül 2019 tarihleri arasında kayıt edilen veriler ve sonuçları aşağıda detaylı bir şekilde sunulmuştur.

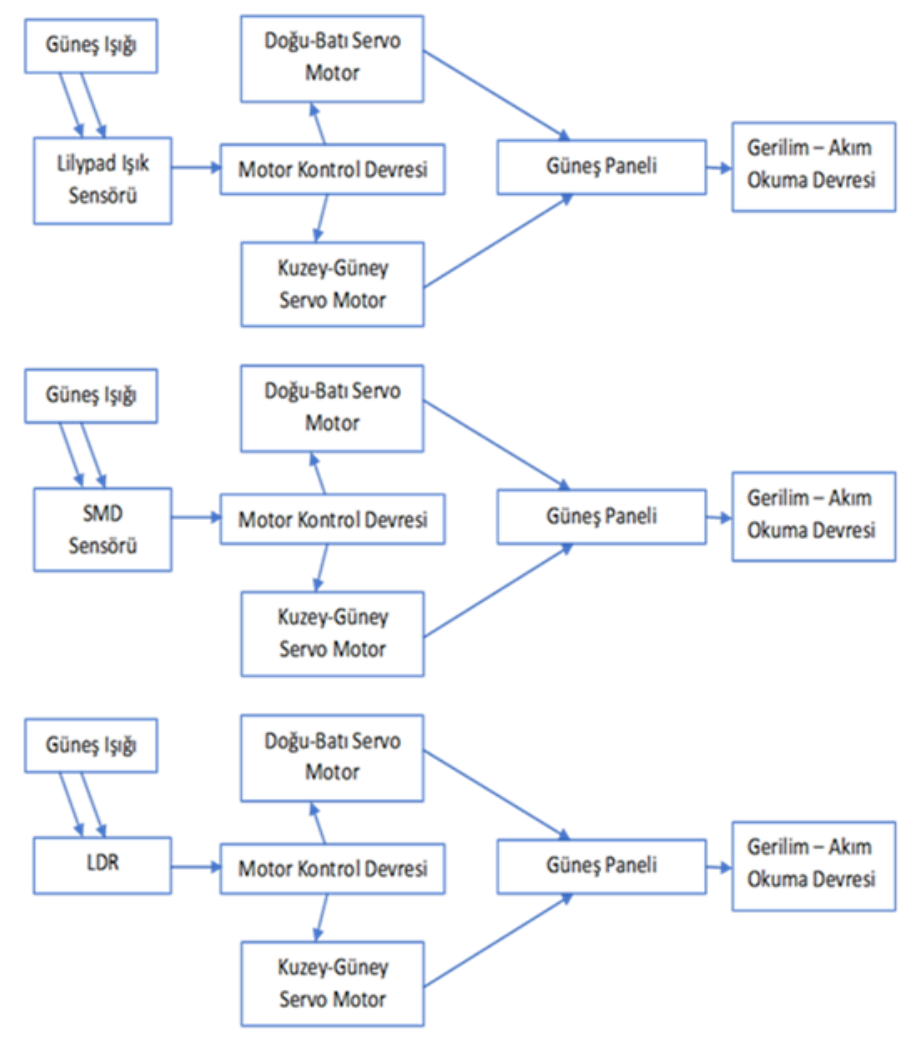

Şekil 4. Güneş takip sistemin blok diyagramı

Güneș takip sisteminin blok diyagramı Şekil 4'te verilmiştir. Sistemin ilk önce motor kontrol devresi çalıştırılmadan sabit konumda gerilim- akım değerleri kaydedilmiştir. Daha sonra güneş takip sistemine algılayıcılar ilave edilip motor kontrolü sağlanmıştır. Sistemden hareketli konumda gerilim -akım değerleri alınmıştır. Her iki düzenekten veriler kaydedilip elde edilen sonuçlar ışığında tahmin yapılmıştır.

Güneş takip sisteminden hareketli konumda akım ve gerilim değerleri kaydedilmiştir. Kaydedilen veri seti bir dakikalık aralıklarla üç haftalık veriyi içermektedir. Verilerden elde edilen bulguların saatlik ortalamaları dikkate alınmıştır. Sistemin 24.09.2019 tarihli saatlik enerji üretimi Tablo 5'te verilmiştir.

Tablo 5. 24.09.2019 tarihli saatlik enerji üretimi

\begin{tabular}{l|c|c|c|c|c|c|c|c|c|c|c|c|c}
\hline Saat & $\mathbf{1 - 6}$ & $\mathbf{7}$ & $\mathbf{8}$ & $\mathbf{9}$ & $\mathbf{1 0}$ & $\mathbf{1 1}$ & $\mathbf{1 2}$ & $\mathbf{1 3}$ & $\mathbf{1 4}$ & $\mathbf{1 5}$ & $\mathbf{1 6}$ & $\mathbf{1 7}$ & $\mathbf{1 8 - 2 4}$ \\
\hline LilyPad & 0 & 2 & 11 & 23 & 27 & 27 & 27 & 26 & 24 & 8 & 2 & 1 & 0 \\
\hline$S M D$ & 0 & 2 & 18 & 36 & 39 & 40 & 40 & 39 & 37 & 29 & 7 & 2 & 0 \\
\hline$L D R$ & 0 & 2 & 19 & 37 & 41 & 42 & 42 & 41 & 39 & 30 & 7 & 2 & 0 \\
\hline
\end{tabular}

Tablo 5'te belirli saat aralıklarında farklı üretim değerleri gözlenmiştir. Güneş 1şınımının en yüksek olduğu zamanlar maksimum değerlere ulaşılmıştır. Aynı zamanda ışınımın olmadığı durumda da üretim olmamıştır. Sistemin güneş ışığına maruz kalma oranına göre enerji üretimi değişkenlik göstermiştir. 


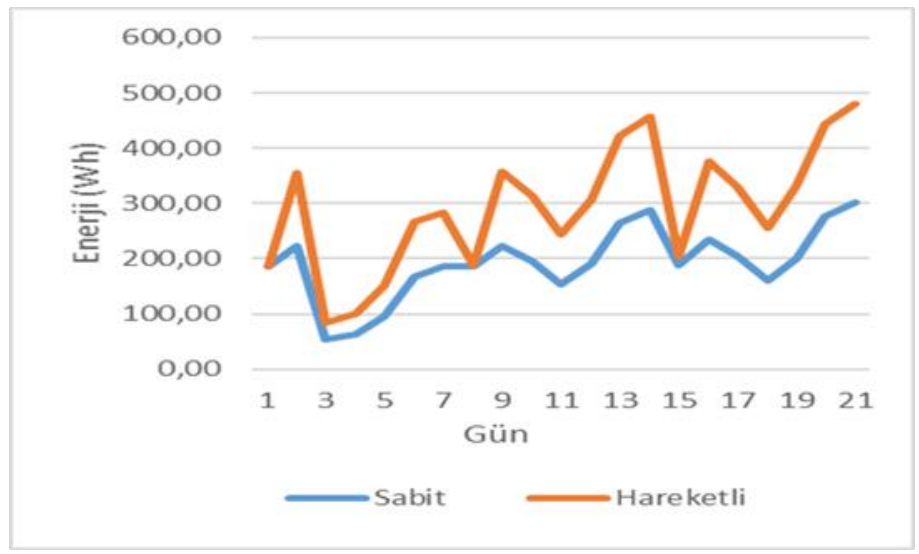

\section{Şekil 5. LilyPad Işsk Sensörlü sistemin hareketli ve sabit konumdaki enerji üretimi}

Şekil 5'te LilyPad Işık Sensörlü sistemin hareketli ve sabit konumdaki toplam enerji üretim değerleri görülmektedir. Değerler gün içinde güneş 1şınımı şiddetinin farklılığına ve olası dış etkenlere bağlı olarak değişiklik göstermektedir.

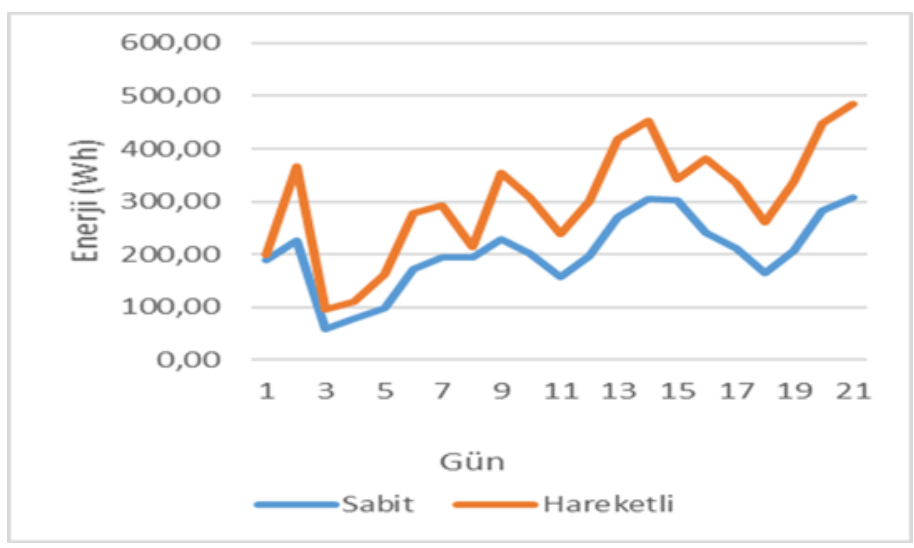

Şekil 6. SMD Sensörlü sistemin hareketli ve sabit konumdaki enerji üretimi

Şekil 6'da SMD Sensörlü sistemin hareketli ve sabit konumdaki toplam enerji üretim değerleri görülmektedir. Elde edilen değerlere göre hareketli sistemde enerji üretimi artış göstermektedir. Güneş açısını yakalamaya yönelik hareketli sistemin konumlandırılması sabit konuma nazaran daha fazla enerji üretimi sağlamıştır.

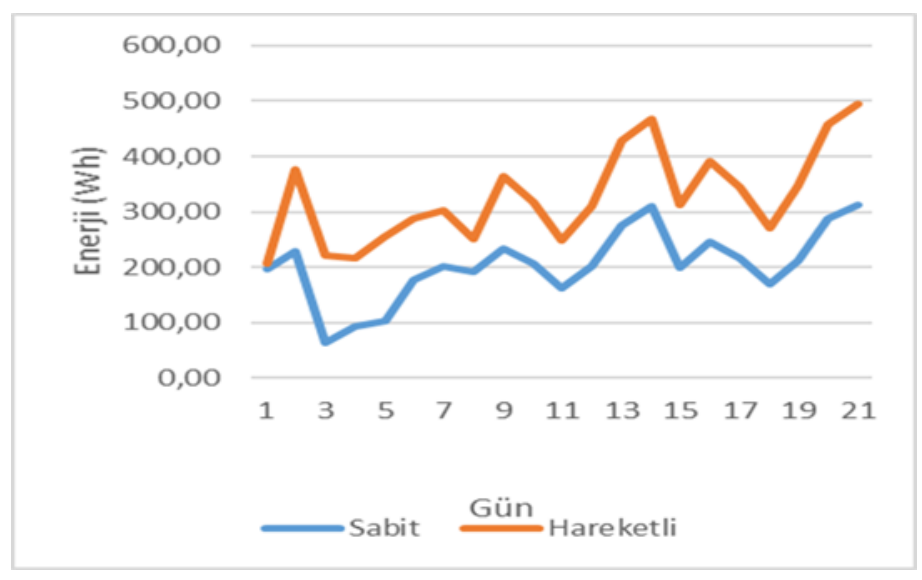

Şekil 7. LDR'li sistemin hareketli ve sabit konumdaki enerji üretimi
Şekil 7'de LDR'li sistemin hareketli ve sabit konumdaki toplam enerji üretim değerleri görülmektedir. Elde edilen veriler hareketli sistemde sabit sisteme göre daha fazla enerji üretimi yapıldığını göstermektedir.

Her üç sistemde günlük dakikalık periyotlarla akım ve gerilim değerleri ölçülmüştür. Üç haftalık zaman dilimi içinde sabit ve hareketli sistemde elde edilen üretim değerleri Tablo 6 'da gösterilmiştir.

\section{Tablo 6. Toplam enerji üretimleri}

\begin{tabular}{l|c|c|c|c|c|c}
\hline & \multicolumn{2}{|c|}{ LilyPad } & \multicolumn{2}{c|}{ SMD } & \multicolumn{2}{c}{ LDR } \\
\hline Hafta & Sabit & Hareketli & Sabit & Hareketli & Sabit & Hareketli \\
\hline $\mathbf{I}$ & 1249 & 1794 & 1256 & 1829 & 1228 & 1864 \\
\hline $\mathbf{2}$ & 1778 & 2318 & 1788 & 2353 & 1748 & 2388 \\
\hline $\mathbf{3}$ & 1846 & 2550 & 1846 & 2585 & 1809 & 2620 \\
\hline
\end{tabular}

Sistemlerin kontrol devreleri aktif olmadan sabit konumdada üretimleri farklı olmuştur. Kullanılan güneş panelleri aynı marka ve aynı güç çıktısına sahiptir. Fakat panellerin sürekli deney çalışmalarında kullanılması yapısal olarak farklı çıkış elde etmeye sebebiyet vermiştir. Buna ek olarak sistemlerin uygulama sahasında gölgeleme ve panel yüzeyinde kirlilik faktörü de etkili olmuştur. Sistemlerin konumlandırılması maksimum güneş ışı̆̆ına maruz kalacak şekilde yapılmıştır.

Sistemlerin kontrol devresi çalıştırılıp hareketli konumda üretimleri kaydedilmiştir. Elde edilen veriler sabit konumdaki üretimlere göre yüksektir. Üç haftalık veriler sonucunda toplam üretim dğerlerine göre sistemlerin verimlilik oranları belirlenmiştir. Lilypad sensörlü sistemden toplam $6663 \mathrm{Wh}$ enerji üretilmiştir. Aynı sistem sabit konumda $4875 \mathrm{Wh}$ üretim yapmıştır. SMD sensörlü sistemden toplam $6768 \mathrm{Wh}$ enerji üretilmiştir. Aynı sistem sabit konumda $4889 \mathrm{Wh}$ üretim yapmıştır. LDR sensörlü sistemden toplam $6873 \mathrm{Wh}$ enerji üretilmiştir. Aynı sistem sabit konumda $4786 \mathrm{Wh}$ üretim yapmıştır.

Elde edilen veriler sşı̆̆ında tahmin yöntemi olarak yapay sinir ağ kullanılmıştır. Güneş takip sisteminden elde edilen verilerle MATLAB üzerinde Yapay Sinir Ağları ile tahmin yapabilmek için veri setinde düzenlemeler yapılmıştır. İlk önce veri setindeki değerler normalize edilmiştir. Elde edilen değerler transpoze edilmiştir. $\mathrm{Bu}$ sayede veriler MATLAB'da kullanılacak matris haline dönüştürülmüştür. Programda kullanılmaya uygun hale getirilen dizi üzerinde girdi ve çıktı değişkenleri tanımlanmıştır. Yapay sinir ağları fonksiyonu oluşturulduktan sonra tahmin sistemi çalıştırılmıştır. Sistemde hata değerleri belirtilen değerlere yaklaşana kadar işleme devam edilmiştir. Yapay sinir ağıyla oluşturulan modelde girdi olarak güneş 1şııımı şiddeti verileri kullanılırken çıktı olarak panelin çıkış gücü elde edilmişsir. 


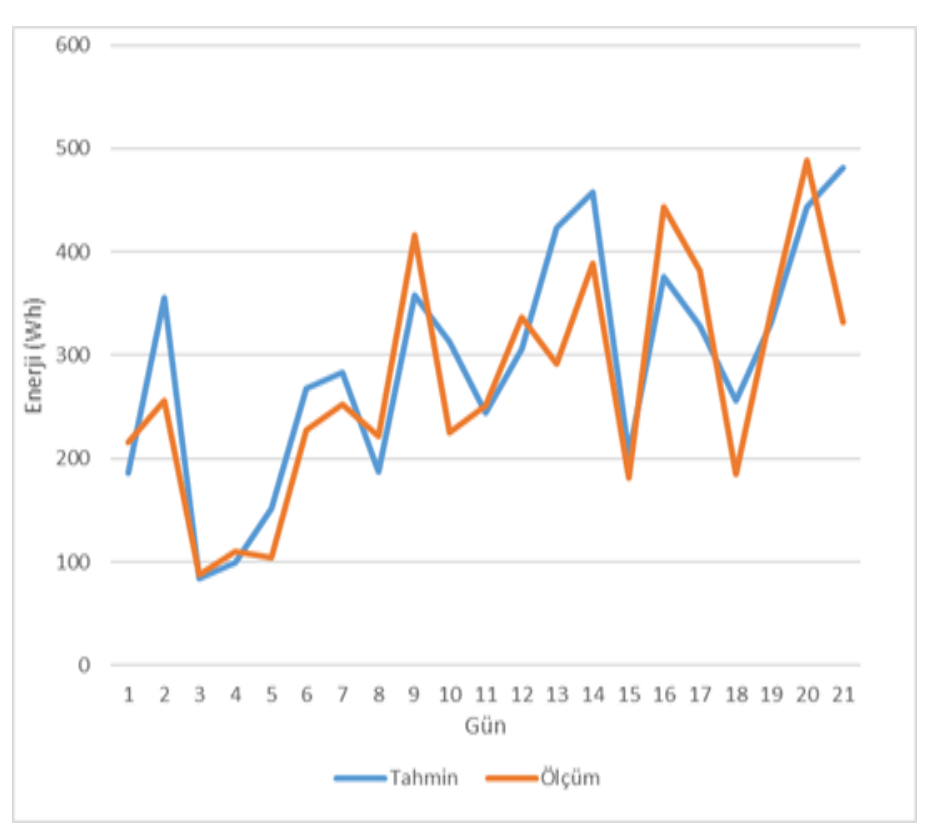

Şekil 8. LilyPad Işık Sensörüne ait ölçülmüş verilerin ve test çıktılarının aynı grafik üzerinde görünümü

Şekil 8 incelendiğinde LilyPad Işık Sensörüne ait ölçülmüş verilerin ve test çıktılarının aynı grafik üzerinde görünümü verilmiştir. Kaydedilen veri sayısının az olması yapılan tahmin ile ölçülen değerlerler arasındaki hata oranının fazla olmasına sebebiyet vermiştir.

\section{Giriş}

Güneş enerji potansiyelinin yüksek olması artan enerji talebini karşılamada umut vaat etmektedir. Güneş enerjisinin sürekli olmaması bu sistemlerin anlık olarak maksimumum verimlilikle çalıştırılmasını gerektirir. Güneş enerji sistemlerinde kullanılan panellerin verimleri çok yüksek değildir. Güneş enerji sistemlerden daha yüksek verimlilikle enerji üretmek için güneş enerjisi takip sistemleri gündeme gelmektedir. Güneş takip sistemleri sabit sistemlere göre daha fazla güç çıktısı üretmektedir. Bu çalışmada deneysel amaçlı iki eksenli bir güneş takip sistemi tasarlanmış ve tasarlanan sistem üzerinden veriler elde edilmiştir. Mekanizmada hareketi sağlamak için servo motor kullanılmıştır. Üç farklı algılayıcı türü ayı anda üç sisteme monte edilip ürettikleri akım gerilim değerleri karşılaştırılmıştır. Yapılan çalışmada güneş panellerinin sabit ve hareketli konumda toplam üretimleri karşılaştırıldığında hareketli konumda sabit konuma göre; LilyPad Işık Sensörlü sistemde \%36,68 oranında, SMD Sensörlü sistemde \%38,42 ve LDR'li sistemde \%43,58 oranında artış görülmüştür.

Hareketli konumda algılayıcıların performans1 karşılaştırılmıştır. Şekil 9'da algılayıcıların üç haftalık üretim değerleri çıktılarının durumu gösterilmiştir. Sistemlerin performansı birbiriyle karşılaştırıldığında en iyi sonuç LDR monte edilen güneş takip sisteminden alınmıştır. Diğer iki sistemin üretim performansı birbirine yakın değerler almıştır. Bunu sebebi ise bu iki sistemde kullanılan algılayıcıların benzer yapıda olmasıdır. $\mathrm{Bu}$ iki sistemde kullanılan algılayıcılar genellikle küçük boyutta uygulamalarda kullanılmaktadır. Bu iki sistemin güç çıktısını artırmak için daha fazla sayıda sensör kullanılarak yüzey alanı artırılabilir. $\mathrm{Bu}$ sayede alınan güç çıktıları iyileştirilebilir.

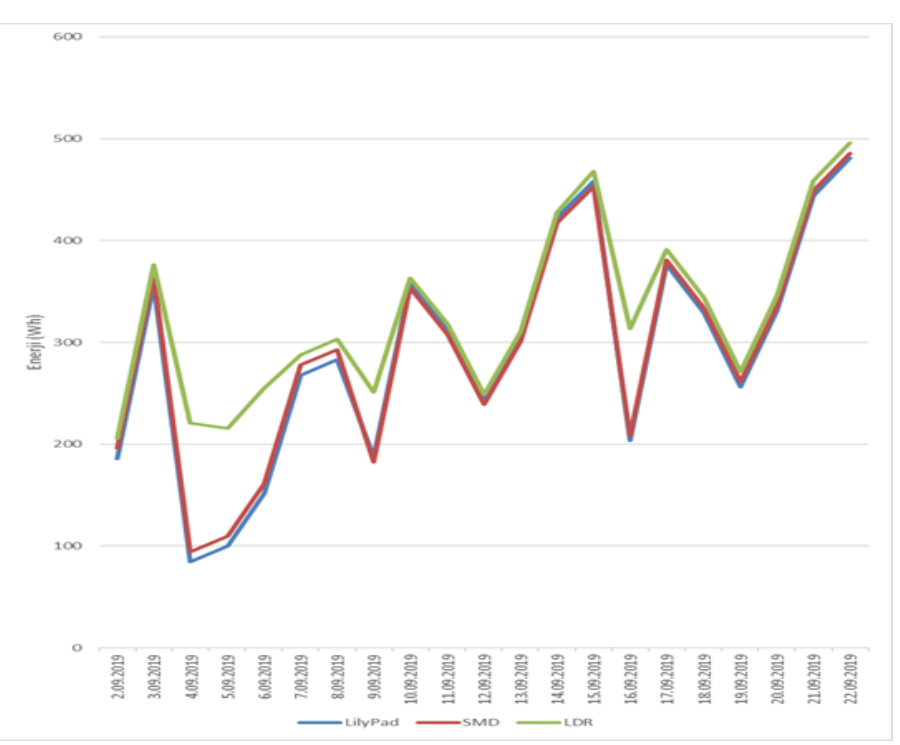

Şekil 9. Algılayıcıların üç haftalık üretim değerleri

Literatürde güneş takip sistemleri konusu üzerinde birçok çalışma mevcuttur. Tek ve çift eksenli ya da kontrol mekanizmasına dayalı farklı metodolojiler kullanılmıştır. Literatürde yapılan çalışmaların verimlilik oranı Tablo 7'de gösterilmiştir.

Tablo 7. Literatürde yapılan çalışmaların verimlilik oranı

\begin{tabular}{l|c}
\hline Yapılan Çalışmalar & Verimlilik Oranı \% \\
\hline Jamroen vd. & 44.89 \\
\hline Makhija vd. & 37 \\
\hline Mane vd. & 26.42 \\
\hline Mohaimin vd. & $8-12$ \\
\hline Smirnov vd & 33 \\
\hline Awad vd. & 25 \\
\hline
\end{tabular}

Genel olarak güneş takip sistemlerinin sabit sistemlere göre verimliliği yüksektir. Yapılan çalışmalar güneş takip sistemlerinin sabit sistemlere göre daha yüksek enerji çıktısı verdiğini göstermektedir. Tek veya çift eksenli farklı kontrol metodolojileri kullanan sistemlerde algılayıcı olarak LDR kullanılmıştır. Farklı geometride ve sayıda LDR kullanılarak verimlilik oranları araştırılmıştır. Bu çalışmada LDR kullanılan sistemin toplam üretiminde $\% 43,58$ oranında bir artış görülmüştür.

Verimliliği yüksek olmasına karşın güneş takip sistemlerinde birçok problem oluşmaktadır. Bu çalışmada düşük maliyetle bir tasarım yapılmıştır. Sistem devreye alınmadan önce kış aylarında çevresel etkilere karşı dayanımı gözlemlenmiştir. Sistemden kısa dönem veri alımında yapısında bozulma olmamıştır. Uzun vadede veri alımı yapılacaksa rüzgar sensörü eklemek makul olacaktır. Deney düzeneği kurulan alan çok rüzgar almaktadır. Bu durum sistemde rüzgar şiddetine bağlı problemler yaratabilmektedir. Rüzgar sensörü kullanmak olası arıza durumlarının önüne geçmemizi sağlayabilmektedir.

Güneş takip sistemleri sabit sistemlere göre daha fazla enerji üretimi sağlar. $\mathrm{Bu}$ sistemler sabit sistemlerden farklı olarak hareketli bir yapıya sahiptir. $\mathrm{Bu}$ sayede güneş ışınlarının geliş açısına doğru yönelerek sistemin maksimum verimlilikle üretim yapmasına olanak sağlamaktadır. Sistemin yüksek verimlilik 
sağlamasına karşın hareket mekanizması ve güneş 1şı̆̆ı algılama donanımları ekstra bir maliyet ortaya çıkarmaktadır. Güneş takip sistemlerinin konumlandırılması detaylı bir fizibilite çalışması gerektirmektedir. Güneş takip sistemlerinin konumlandırılmasının iyi yapılamaması bu sistemlerden alınan verimin düşmesine sebebiyet verebilmektedir.

\section{Kaynakça}

Alif Ismail, M., Ramanathan, K.A., Hafizi Idris, M., AnandaRao, K., Mazlan, M., Fairuz, N., (2020). Improving the Performance of Solar Panels by The Used of Dual Axis Solar Tracking System with Mirror Reflection, Journal of Physics: Conference Series, 1432, 012060.

Allamehzadeh, H., (2019). An Update on Solar Energy and Sun Tracker Technology with a Dual Axis Sun Tracker Application, IEEE 46th Photovoltaic Specialists Conference (PVSC), Chicago, IL, USA, 2037-2044.

Al-Rousan, N., Mat Isa, N.A., Mat Desa, M.K., (2020). Efficient Single and Dual Axis Solar Tracking System Controllers Based on Adaptive Neural Fuzzy Inference System, Journal of King Saud University- Engineering Sciences.

Altayeb, M., Abdalla, S., Mustafa, A.H., (2018). Dual Axis Solar Sun Tracking System Based on GPS Satellite Receiver and Embedded System, 2018 International Conference on Computer Control Electrical and Electronics Engineering (ICCCEEE), Khartoum, 1-4.

Amelia, A.R., Irwan, Y.M., Safwati, I., Leow, W.Z., Mat, M.H., Rahim, M.S.A., (2020). Technologies of Solar Tracking Systems: A Review, IOP Conference Series: Materials Science and Engineering, 767, 012052.

Ammach, S., Attia, A., (2019). Design and Implementation of Autonomous Energy Efficient Solar Tracking System for PV Power Plants, International Conference on Electrical and Computing Technologies and Applications, ICECTA 2019, 8959537.

Awad, S.R., Al Jbaar, M.A., Abdullah, M.A.M., (2020). Efficient and Low-Cost Arduino based Solar Tracking System, IOP Conference Series: Materials Science and Engineering, 745, 012016.

Awasthi, A., Shukla, A.K., Murali Manohar, S.R., Dondariya, C., Shukla, K.N., Porwal, D., Richhariya, G., (2020). Review on Sun Tracking Technology in Solar PV System, Energy Reports, 6, 392-405.

Away, Y., Ikhsan, M., (2017). Dual-axis Sun Tracker Sensor Based on Tetrahedron Geometry, Automation in Construction 73, 175-183.

Benaboud, A., (2020). A Special Application of Power Electronics to the Field of Photovoltaic, Lecture Notes in Electrical Engineering, 624, 24-33.

Farhan, A.J., (2020). Fabrication and Development Low Cost Dual Axis Solar Tracking System, IOP Conference Series: Materials Science and Engineering, 757, 012042.

Jamroen, C., Komkum, P., Kohsri, S., Himananto, W., Panupintu, S., Unkat, S., (2020). A Low-cost Dual-axis Solar Tracking System Based on Digital Logic Design: Design and Implementation, Sustainable Energy Technologies and Assessments, 37, 100618.

e-ISSN: 2148-2683
Makhija, S., Khatwani, A., Khan, M.F., Goel, V., Roja, M.M., (2017). Design \& Implementation of An Automated Dualaxis Solar Tracker With Data-logging, 2017 International Conference on Inventive Systems and Control (ICISC), Coimbatore, pp. 1-4.

Mane, S.G., Korachagaon, I., Hans, M.R., Sawant, A.S., (2018). Simulation of Dual Axis Solar Tracking System, 2018 International Conference on Information Communication Engineering and Technology (ICICET), Pune, 1-5.

Mohaimin, H., Uddin, M.R., Hashim, H., Tuah, N., Zahari, M.R., (2018). Design and Simulation of Single-axis and Dual-axis Solar Tracking Systems, 7th Brunei International Conference on Engineering and Technology 2018 (BICET 2018), Bandar Seri Begawan, Brunei, 1-4.

Mohaimin, A.H., Uddin, M.R., Law, F.K., (2018). Design and Fabrication of Single-Axis and Dual-Axis Solar Tracking Systems, 2018 IEEE Student Conference on Research and Development (SCOReD), Selangor, Malaysia, 1-4.

Mohd Said, M.N.A., Jumaat, S.A., Jawa, C.R.A., (2020). Dual Axis Solar Tracker With Iot Monitoring System Using Arduino, International Journal of Power Electronics and Drive Systems, 11, 451-458.

Mustafa, F.I., Al-Ammri, A.S., Ahmad, F.F., (2017). Direct and Indirect Sensing Two-axis Solar Tracking System, 2017 8th International Renewable Energy Congress (IREC), Amman, $1-4$.

Mustafa, F.I., Shakir, S., Mustafa, F.F., Naiyf, A.T., (2018). Simple Design and Implementation of Solar Tracking System Two Axis With Four Sensors for Baghdad City, 2018 9th International Renewable Energy Congress (IREC), Hammamet, 1-5.

Natarajan, S.K., Kumar, A., Mohamed, R., Rathna, R., Mondal, S., Suraparaju, S.K., (2019). Design and Development of Dual Axis Sun Tracking System for Floating PV Plant, IOP Conference Series: Earth and Environmental Science, 312, 012001.

Pattanaik, P., (2019). Dual Axis Tracker for Photovoltaic Panel, International Journal of Innovative Technology and Exploring Engineering, 8, 906-910.

Salih, N.M., Said, M.S.M., Jamil, N., Davion, T., Yahaya, A.H., (2019). System Identification of a Solar Maximum Power Point Tracking System for Dual Axis, International Journal of Innovative Technology and Exploring Engineering, 8, 5653-5657.

Smirnov, A.A., Vozmilov, A.G., Sultonov, O.O., (2020). Investigating the Effectiveness of Solar Tracking for PV Facility in Chelyabinsk, Lecture Notes in Electrical Engineering, 641, 501-508.

Tiwari, N., Soni, R., Saraswat, A., Kumar, B., (2020). Comparative Simulation Study of Dual-axis Solar Tracking System on Simulink Platform, Lecture Notes in Electrical Engineering, 607, 359-365.

Zhu, Y., Liu, J., Yang, X., (2020). Design and Performance Analysis of A Solar Tracking System With A Novel Singleaxis Tracking Structure to Maximize Energy Collection Applied Energy, 264, 114647. 